\title{
Kimberlitic olivine attrition: Fingerprinting environments and timescales
}

\author{
Thomas J. Jones ${ }^{1}$ \& J. K. Russell ${ }^{2}$ \\ ${ }^{I}$ Department of Earth Sciences, Durham University, South Road, Durham, DHI 3LE, UK, \\ t.j.jones@durham.ac.uk; tomij7@gmail.com \\ ${ }^{2}$ Department of Earth, Ocean \& Atmospheric Sciences, University of British Columbia, Vancouver, British \\ Columbia, V6T 1Z4, Canada, jkr2002@gmail.com
}

\section{Introduction}

Attrition results in the size reduction and rounding of particles and occurs in a wide variety of geological environments. From the Engineering Sciences, we identify two modes of attrition (Bemrose and Bridgwater 1987; Xiao et al. 2014; Jones et al. 2017): (1) fragmentation and (2) abrasion. Fragmentation (1) is described as particle fracturing where the original particles, often referred to as the parent particles, break-down to form a group of similarly-sized daughter particles. A 'critical' collision which achieves fragmentation typically occurs through direct impact with other particles or with a hard surface at, or above, a threshold velocity. Abrasion (2) describes a less energetic process wherein the rough edges or asperities of the parent particles are rounded off to leave the parent particles with smoother surfaces and morphologies. An additional by-product of abrasion processes is the production of very fine particles. There are several factors that control the rate of attrition and they can be broadly divided into two groups: particle properties and environmental factors. Particle properties include, but are not limited to, size, shape, surface texture, particle size distribution, hardness and internal defects/flaws. Environmental factors affecting rates of attrition include: particle residence times, particle concentrations, temperature, pressure, and differential velocities (i.e. between colliding particles or between particles and confining wall). Attrition is most successful when velocities are high, particle concentrations are high, particle shapes are irregular, residence times are long and particle size distributions are poorly sorted.

Particle attrition affecting kimberlitic minerals potentially operates in several different environments between the lithospheric mantle and the Earth's surface. Attrition of kimberlitic indicator minerals during sedimentological transport within glacial and fluvial deposits has been studied and used in exploration to assess distance to the source kimberlite pipe (McCandless 1990; Afanas' ev et al. 2008). More recent work has evaluated the potential for, and consequences of, attrition of mantle cargo attending the transport, fragmentation, and emplacement/eruption of kimberlite magma. Specifically, Jones et al. (2014) and Brett et al. (2015) suggested that the shapes and surfaces of mantle-derived xenocrystic minerals could be a strong indicator of turbulent ascent of kimberlite magmas through the lithospheric mantle and within subsurface feeder dykes. Within any geological environment, the nature of particle-particle interactions can be highly variable, however, at a firstorder attrition operates with two contrasting styles: (1) high velocity, transient particle-particle or particle-wall interactions and (2) lower energy sustained abrasive contacts. Here, these two attrition styles are investigated with contrasting experiments performed in a fluidized bed and a tumbling mill respectively.

\section{Methods}

All experiments were performed on crushed dunite that was sieved to a restricted, narrow range of grain sizes which constituted the feed for each experiment. Specific operating conditions for the experiments performed in the fluidized attrition tube (Fig. 1a) and in the tumbling mill (Fig. 1b) are listed in Table 1. At the end of each experiment all the material was recovered and flushed with deisonised water to collect all of the ultra-fine particles. Grain size distrbutions were measurd by dry sieving of all particles measuring $>63 \mu \mathrm{m}$ using a standard stack of Tyler sieves and then by laser particle size analysis on paricles $<63 \mu \mathrm{m}$. We allowed a $63-125 \mu \mathrm{m}$ overlapping grain size range. 


\begin{tabular}{lcc|}
\hline Description & Fluidized Attrition Tube & Tumbling Mill \\
\hline Mass of Feed & $70 \mathrm{~g}$ & $120 \mathrm{~g}$ \\
Feed grain size range & $125-500 \mu \mathrm{m}$ & $1-2 \mathrm{~mm}$ \\
Experiment Duration & $0.5-32 \mathrm{hours}^{-1}$ & $1-30$ days \\
Material bulk velocity & $1.13 \mathrm{~ms}^{-1}$ & $0.27 \mathrm{~ms}^{-1}$ \\
\hline
\end{tabular}

Table 1: Experimental operating conditions.

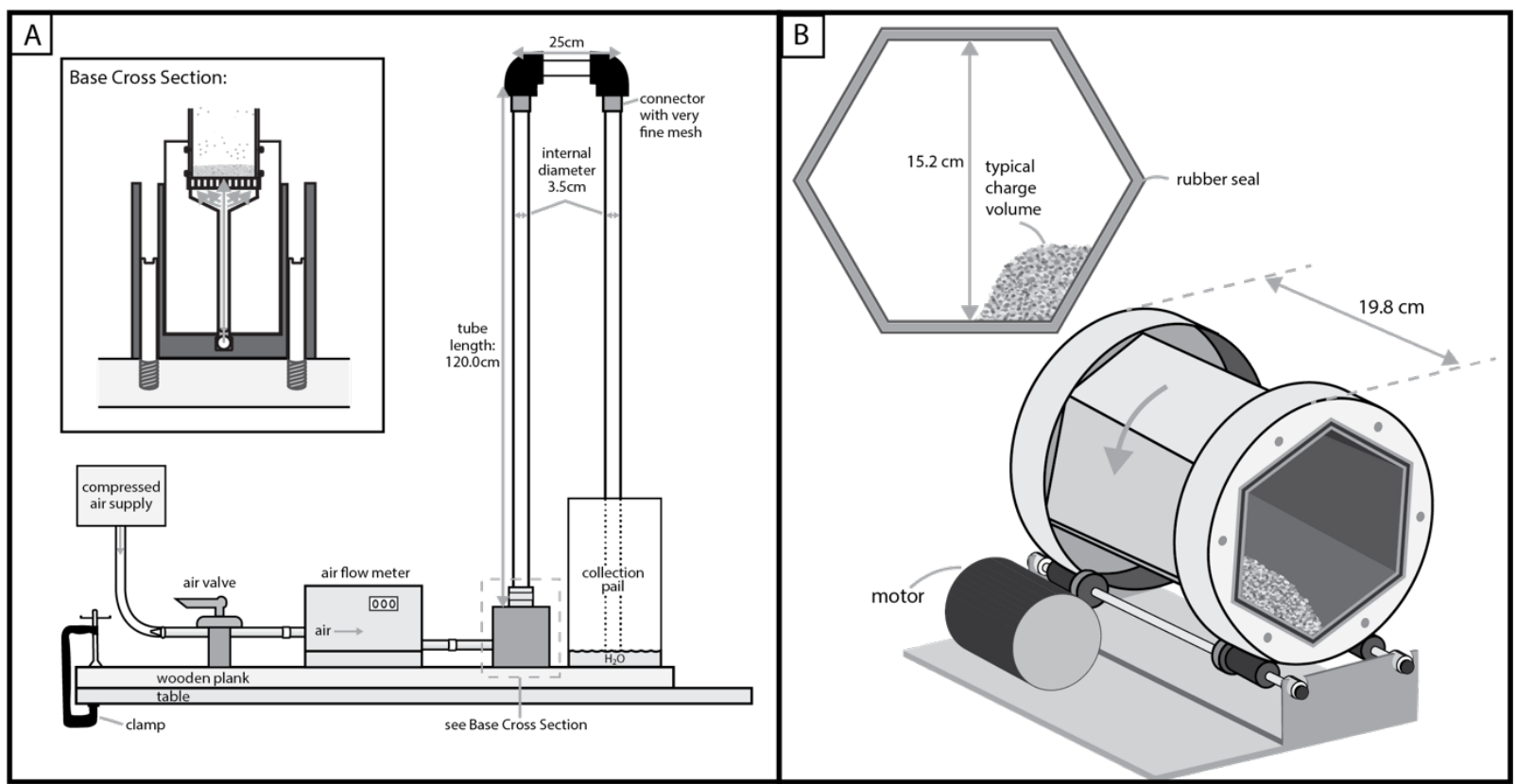

Figure 1: Diagram of (a) fluidized attrition tube and (b) tumbling mill used in this study.

\section{Results and Analysis}

In both the attrition tube and the tumbling mill the olivine feed was systematically reduced in grain size as a function of residence time. Furthermore, this reduction in feed or parent particles is nonlinear in time, such that attrition is faster at short times and slower at longer times (Fig. 2). The reduction in the parent feed can be attributed to the production of smaller daughter particles formed by both fragmentation and abrasion. We find that the rate of fines production (defined as the mass of daughter particles, $\mathrm{m}_{\mathrm{d}}$ normalised to the feed mass, $\mathrm{m}_{0}$ ) is best described as:

$$
\mathrm{m}_{\mathrm{d}} / \mathrm{m}_{0}=a\left(1-e^{-b t}\right)[\text { Eqn. 1] }
$$

where $a$ is the infinite time limit, $b$ is the attrition rate constant and $t$, the residence time reported in hours (Jones et al. 2017). Modelled values for olivine attrition within a fluidized bed and tumbling mill are shown in Figures $2 \mathrm{a}$ and $\mathrm{b}$ respectively.

We note that both the infinite time limit and the attrition rate constant are higher for the fluidized bed relative to the tumbling mill. Firstly, this suggests that the attrition tube can produce more stable daughter products relative to the parent feed. It is likely that this is a direct consequence of the higher energy environment ( $\sim$ higher velocity) that the olivine particles experience within the attrition tube. Higher energy fragmentation environments lead to a finer stable grain size (Jones \& Russell., accepted pending revisions). Secondly, the attrition rate is an order of magnitude faster in the fluidized bed. Daughter fragments start to reach a near stable size after $\sim 5$ hours of attrition rather than $\sim 80$ hours as observed in the lower energy tumbling mill. Faster early attrition is due to rapid fragmentation of residual particle defects/flaws and easy abrasion of highly irregular external morphologies, producing abundant ultra-fine chips. Furthermore, this can be visualised through scanning electron microscopy of individual particles. We observe the highly irregular particle 
exteriors of the feed to become smoothed during attrition. Abrupt ridges and fracture planes are rounded and surfaces become coated in ultra-fine chips with increased residence time.
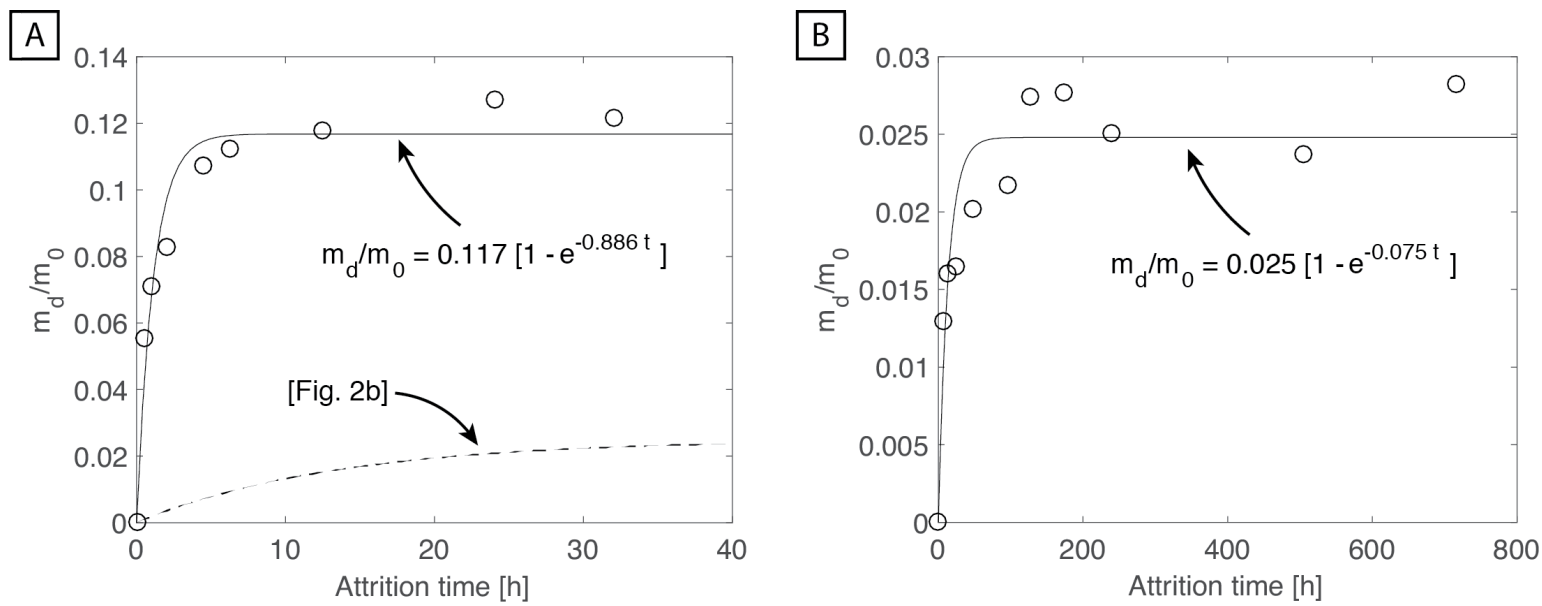

Figure 2: Fines production model (Equation 1) for (a) fluidized attrition tube and (b) tumbling mill used in this study. Note the change in axis scale between the different plots.

\section{Implications and Future Work}

Our results elucidate the effects of transport conditions and durations on specific olivine crystal size populations. We show that two very different energy environments, which are relevant to a wide range of natural systems, support particle attrition. The rates and extents of attrition for a similar feed are shown to be strongly controlled by the environment and residence time. This allows for a preliminary assessment of the attrition potential of a system depending on the environment that is considered. For example, olivine transported post-eruption in a river bed will experience little grain size modification compared to turbulent sub-surface transport. Once the attrition environment is known, our fines production model can help estimate the residence time/ transport distance a particle population has experienced. Future work will involve quantitative shape analysis on the experimental products and more experiments at different velocities (e.g. higher energies).

\section{References}

Afanas' ev VP, Nikolenko EI, Tychkov NS, et al (2008) Mechanical abrasion of kimberlite indicator minerals: experimental investigations. Russ Geol Geophys 49:91-97.

Bemrose CR, Bridgwater J (1987) A review of attrition and attrition test methods. Powder Technol 49:97-126.

Brett RC, Russell JK, Andrews GDM, Jones TJ (2015) The ascent of kimberlite: Insights from olivine. Earth Planet Sci Lett 424:119-131. doi: http://dx.doi.org/10.1016/j.eps1.2015.05.024

Jones TJ, Russell JK, Lim CJ, et al (2017) Pumice attrition in an air-jet. Powder Technol 308:298305. doi: 10.1016/j.powtec.2016.11.051

Jones TJ, Russell JK, Porritt LA, Brown RJ (2014) Morphology and surface features of olivine in kimberlite: implications for ascent processes. Solid Earth 5:313.

Jones TJ, Russell JK (Accepted Pending Revisions) Ash production by attrition in volcanic conduits and plumes. Scientific Reports.

McCandless TE (1990) Kimberlite xenocryst wear in high-energy fluvial systems: Experimental studies. J Geochemical Explor 37:323-331.

Xiao G, Grace JR, Lim CJ (2014) Evolution of Limestone Particle Size Distribution in an Air-Jet Attrition Apparatus. Ind Eng Chem Res 53:15845-15851. 